\title{
Correction to: DNA Barcoding and Pharmacovigilance of Herbal Medicines
}

\author{
Hugo J. de Boer ${ }^{1,2} \cdot$ Mihael C. Ichim ${ }^{3} \cdot$ Steven G. Newmaster ${ }^{4}$
}

Published online: 2 January 2021

C) Springer Nature Switzerland AG 2021

\section{Correction to: Drug Saf (2015) 38:611-620 https://doi.org/10.1007/s40264-015-0306-8}

The Conflicts of interest section, which previously read:

"Hugo de Boer, Mihael Ichim and Steven Newmaster have no conflicts of interest that are directly relevant to the content of this study."

should read:

"Hugo de Boer and Mihael Ichim have no conflicts of interest that are directly relevant to the content of this study. Steven Newmaster is a founding member of NHP Research
Alliance, which works on DNA-based validation of herbal supplements."

The original article can be found online at https://doi.org/10.1007/ s40264-015-0306-8.

Hugo J. de Boer

hugo.deboer@ebc.uu.se

1 The Natural History Museum, University of Oslo, Oslo,

Norway

2 Department of Organismal Biology, Evolutionary

Biology Centre, Uppsala University, Norbyvägen 18D,

75236 Uppsala, Sweden

3 NIRDBS/“'Stejarul", Research Centre for Biological Sciences, Piatra Neamt, Romania

4 Centre for Biodiversity Genomics, Biodiversity Institute of Ontario (BIO), University of Guelph, Guelph, ON, Canada 